Check for updates

Cite this: Chem. Sci., 2019, 10, 4684

¿ All publication charges for this article have been paid for by the Royal Society of Chemistry

\section{A modular and concise approach to MIDA acylboronates via chemoselective oxidation of unsymmetrical geminal diborylalkanes: unlocking access to a novel class of acylborons $\dagger$}

\author{
Shengjia Lin, Lucia Wang, Negin Aminoleslami, Yanting Lao, Chelsea Yagel \\ and Abhishek Sharma (D)*
}

Acylboronates represent a very intriguing and rare class of organoboronates. Synthesis of these compounds from readily available substrates under mild conditions and access to novel classes of acylborons has been challenging. We report a novel and concise route to various MIDA acylboronates from terminal alkynes/ alkenes or vinyl boronic esters using unsymmetrical geminal diborylalkanes as key intermediates. The high modularity and mild conditions of this strategy allowed a facile access to acylboronates possessing aliphatic, aromatic as well as the rarer heteroaromatic, alkynyl and $\alpha, \beta$-unsaturated scaffolds. To the best of our knowledge, this is the first report of chemoselective oxidation of geminal diborons as well as synthesis of an $\alpha, \beta$-unsaturated acylboronate.
Received 23rd January 2019 Accepted 20th March 2019

DOI: $10.1039 / \mathrm{c} 9 \mathrm{sc00378a}$

rsc.li/chemical-science studies by Yudin and Bode have led to the emergence of MIDA acylboronates and potassium trifluoroacyl borates (KATs) as a very attractive class of compounds due to their utility for synthesis of rare borylated heterocycles ${ }^{7 \boldsymbol{a}, \boldsymbol{b}}$ and as powerful building blocks for bioorthogonal amide formation and protein ligation. ${ }^{6 d, 9}$

Previous synthetic approaches (Scheme 1(a)) to acylborons involved (i) the reaction of highly nucleophilic boron or organolithiums with carbonyl or boron electrophiles, (ii) oxidative cleavage of alkenyl-2-MIDA boronates using $\mathrm{OsO}_{4} /$ $\mathrm{NaIO}_{4}$ or ozonolysis and (iii) oxidation of $\alpha$-hydroxy MIDA boronates. Despite these notable advances, there are still significant challenges that hamper the broader investigation and application of acylborons. For instance, oxidation of $\alpha$ hydroxy MIDA boronates is a user-friendly strategy, however, synthetic access to $\alpha$-hydroxy MIDA boronates is a major challenge as it involves a six-step route from vinyl boronates (Scheme 1(a)). ${ }^{7 a}$ Furthermore, many useful $\alpha$-hydroxy MIDA boronates are inaccessible through conventional methods. Thus, it will be beneficial to develop novel strategies for synthesis of acylborons that combine the following benefits in a single synthetic method: (i) reduce the number of synthetic steps; (ii) use readily available substrates such as alkynes and alkenes (iii) involve mild reaction conditions and avoid the use of highly basic boron/organolithium reagents or harsh oxidizing reagents and ultra-low temperatures and (iv) most importantly, open-up access to rare and novel classes of acylborons. $^{2 a, 10}$

In order to address the above challenges, we envisioned that a concise and modular access to MIDA acylboronates could be 


\section{(a) Previous approaches}

Nozaki (2007), Aldridge (2015)

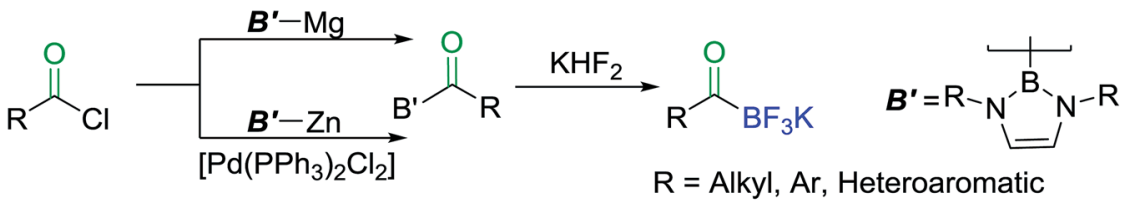

Molander, Bode (2012)

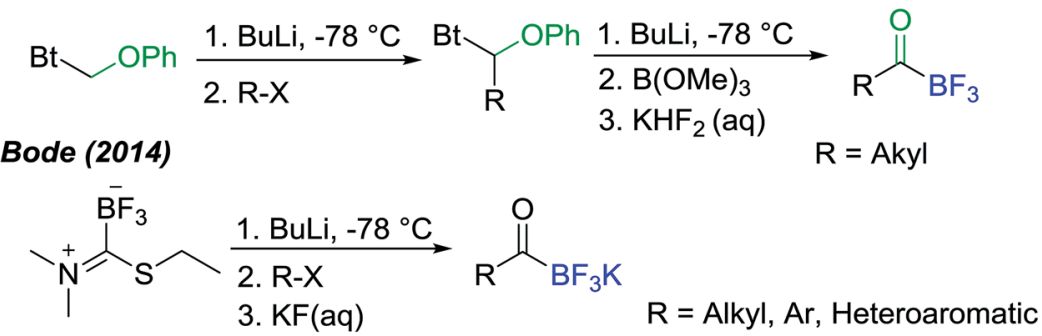

Yudin (2012)
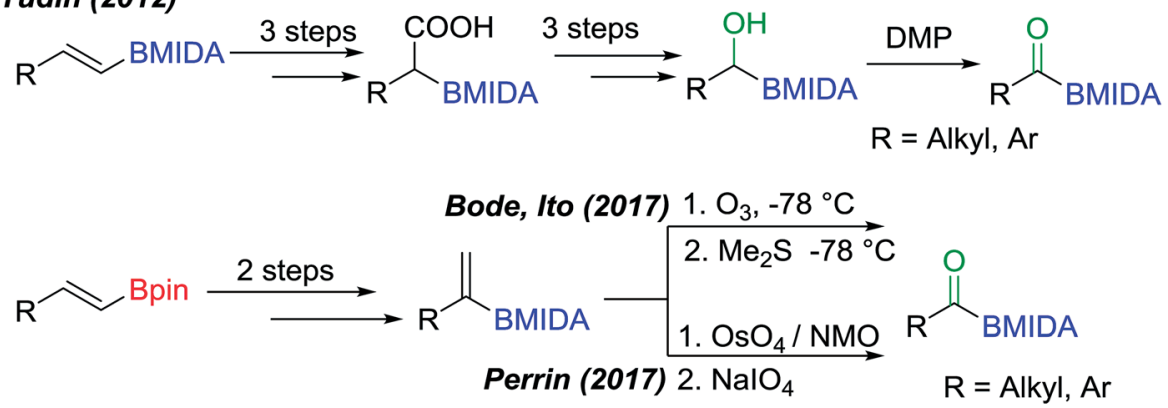

(b) This work
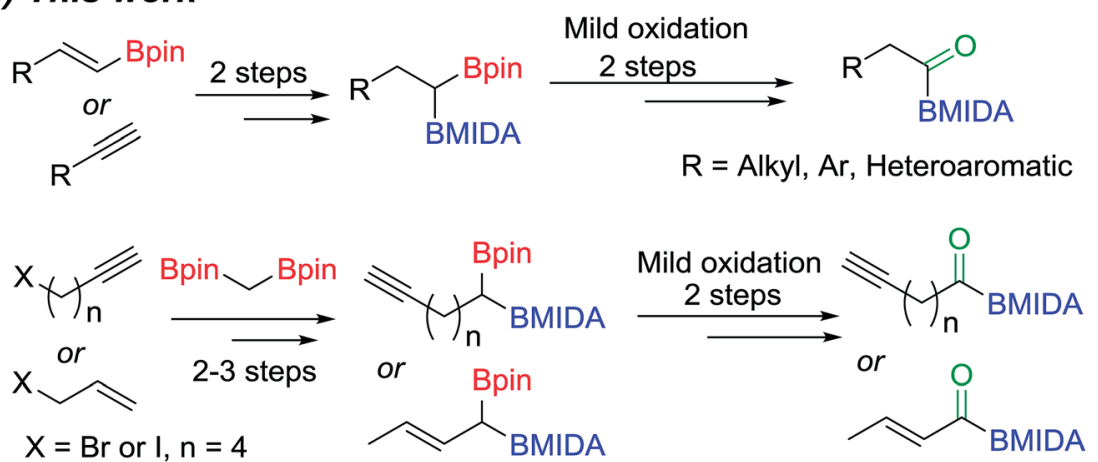

Rare and Novel Acylborons

Scheme 1 (a) Previous synthetic approaches for synthesis of acylborons; (b) the new modular approach to acylboronates via chemoselective oxidation of geminal diborylalkanes.

obtained by chemoselective oxidation of unsymmetrical geminal diborylalkanes (Scheme 1(b)). Geminal diborylalkanes have emerged as attractive building blocks for preparation of a wide range of structurally complex organoborons. ${ }^{11}$ In comparison to other 1,1-organodimetallic reagents, ${ }^{12}$ the geminal organodiboron compounds possess several advantages such as enhanced stability, ease of handling and easy accessibility from abundantly available substrates such as alkynes and alkenes. Previous reports have focused on the application of these geminal diborons for $\mathrm{C}-\mathrm{C}$ bond formation via boron- stabilized carbanion or chemoselective Suzuki coupling. ${ }^{11 a-c, g}$ However, chemoselective oxidation of one of the boron in a geminal diboron compound has not been described before. ${ }^{13}$

\section{Result and discussion}

We hypothesized that mild oxidation of an unsymmetrical diborylalkane possessing geminal $\mathrm{B}(\mathrm{MIDA})$ and $\mathrm{B}(\mathrm{Pin})$ groups should selectively give the $\alpha$-hydroxy MIDA boronate which can then be further oxidized to acylboronates. This strategy would 
drastically reduce the number of $\operatorname{steps}^{7 a}$ required for synthesis of $\alpha$-hydroxy borons and MIDA acylboronates from vinyl boronic esters or even terminal alkynes, which are more easily available and cheaper. Our initial strategy for synthesis of unsymmetrical geminal diboryl alkanes involved the copper catalyzed regioselective hydroboration ${ }^{\mathbf{1 4}}$ of vinyl MIDA boronate with HBpin followed by chemoselective oxidation of the more reactive $\mathrm{B}$ (Pin) group into the $\alpha$-hydroxy MIDA boronate. However, this approach proved unsuccessful as the vinyl MIDA boronate was found to undergo MIDA deprotection under the borylation conditions (Scheme 2) using either $\mathrm{KO} t \mathrm{Bu}$ or the milder $\mathrm{KH}_{2} \mathrm{PO}_{4}$ as a base. Thereafter, we attempted an alternative strategy that involved regioselective dihydroborylation of readily available terminal alkyne into a symmetrical geminal diborylalkane followed by conversion ${ }^{\mathbf{1 5}}$ of one of the pinacol boronic ester

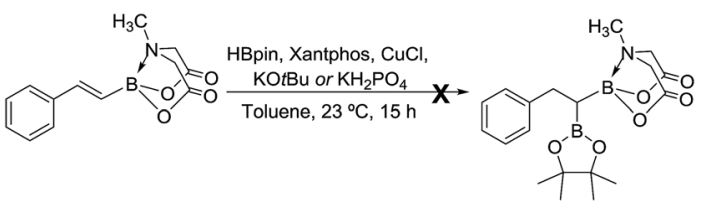

Scheme 2 Attempted synthesis of unsymmetrical geminal diborylalkane from vinyl MIDA boronate.

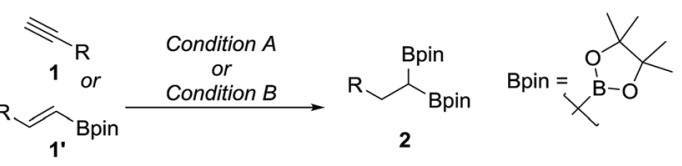

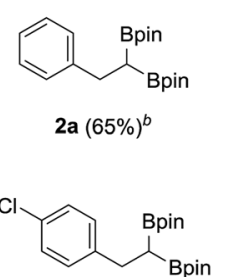

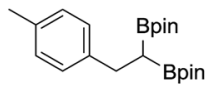

2b $(67 \%)^{a}$

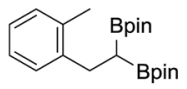

2c $(60 \%)^{a}$<smiles>Fc1ccc(CC(Br)c2ccccc2)c(F)c1</smiles><smiles>CCCCC(Br)c1ccccc1</smiles>

2d $(77 \%)^{b}$<smiles>BrC(Br)CC1CCCC1</smiles><smiles>BrC(Br)CC1CCCCC1</smiles>

2g $(79 \%)^{a}$<smiles>Brc1ccccc1</smiles><smiles>COCCC(Br)c1ccccc1</smiles><smiles>CCCCCCCC(c1ccccc1)c1ccccc1</smiles><smiles>Brc1ccccc1</smiles>

$2 \mathrm{~m}(43 \%)^{a}$<smiles>ClCCCCCC(Br)c1ccccc1</smiles>

2n $(87 \%)^{a}$ $2 f(88 \%)^{b}$

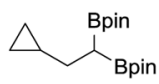

2i $(83 \%)^{b}$<smiles>COC(=O)CCCCC(Br)c1ccccc1</smiles>

2o $(53 \%)^{a}$
Scheme 3 Synthesis of symmetrical geminal diborons from alkynes or alkenes. ${ }^{a}$ Reaction condition $\mathrm{A}$ : terminal alkyne $(1.7 \mathrm{mmol}), \mathrm{CuCl}$ (5.0 mol\%), KOtBu (0.1 equiv.), xantphos (6.0 mol\%), HBpin (2.4 equiv.), toluene, $23^{\circ} \mathrm{C}, 15 \mathrm{~h} .{ }^{b}$ Reaction condition $\mathrm{B}$ : vinyl pinacol boronic ester (2.0 mmol), $\mathrm{CuCl}(5.0 \mathrm{~mol} \%), \mathrm{KOtBu}(0.1$ equiv.), xantphos $(6.0 \mathrm{~mol} \%)$, HBPin (1.2 equiv.), toluene, $23^{\circ} \mathrm{C}, 15 \mathrm{~h}$.
(B(Pin)) groups into $\mathrm{B}(\mathrm{MIDA})$. Thus, reaction of terminal alkynes (1b, $\mathbf{c}, \mathbf{g}, \mathbf{h}, \mathbf{m}-\mathbf{o})$ with HBPin (2.4 equiv.) in the presence of $\mathrm{CuCl}$, xantphos and $\mathrm{KO} t \mathrm{Bu}$ provided the corresponding geminal diboron compounds ( $2 \mathbf{b}, \mathbf{c}, \mathbf{g}, \mathbf{h}, \mathbf{m}-\mathbf{o}$, Scheme 3). Further, a similar strategy was also applicable on vinyl pinacol boronic esters which are also commercially available (1a, d-f, i1, Scheme 3). To convert these symmetrical geminal diborylalkanes into unsymmetrical geminal diborons, several reaction conditions were screened (see ESI, Table S1 $\dagger$ ). Heating the symmetrical diborons with $\mathrm{N}$-methyliminodiacetic $\operatorname{acid}^{\mathbf{1 5}}$ (MIDA, 6 equiv.) in DMSO at $130{ }^{\circ} \mathrm{C}$ in the presence of $\mathrm{HC}(\mathrm{OEt})_{3}$ (ref. 6c) provided best conversion (3a-o, Scheme 4). The conversion of $\mathrm{B}(\mathrm{Pin})$ into $\mathrm{B}(\mathrm{MIDA})$ is known to be a sluggish transformation $^{\mathbf{6 c , 8 a , 1 5}}$ and the yield of this reaction for symmetrical diboron substrates (2a-o, Scheme 4 ) was comparable to the earlier reports that used monoboron substrates. ${ }^{6 c, 8 a}$

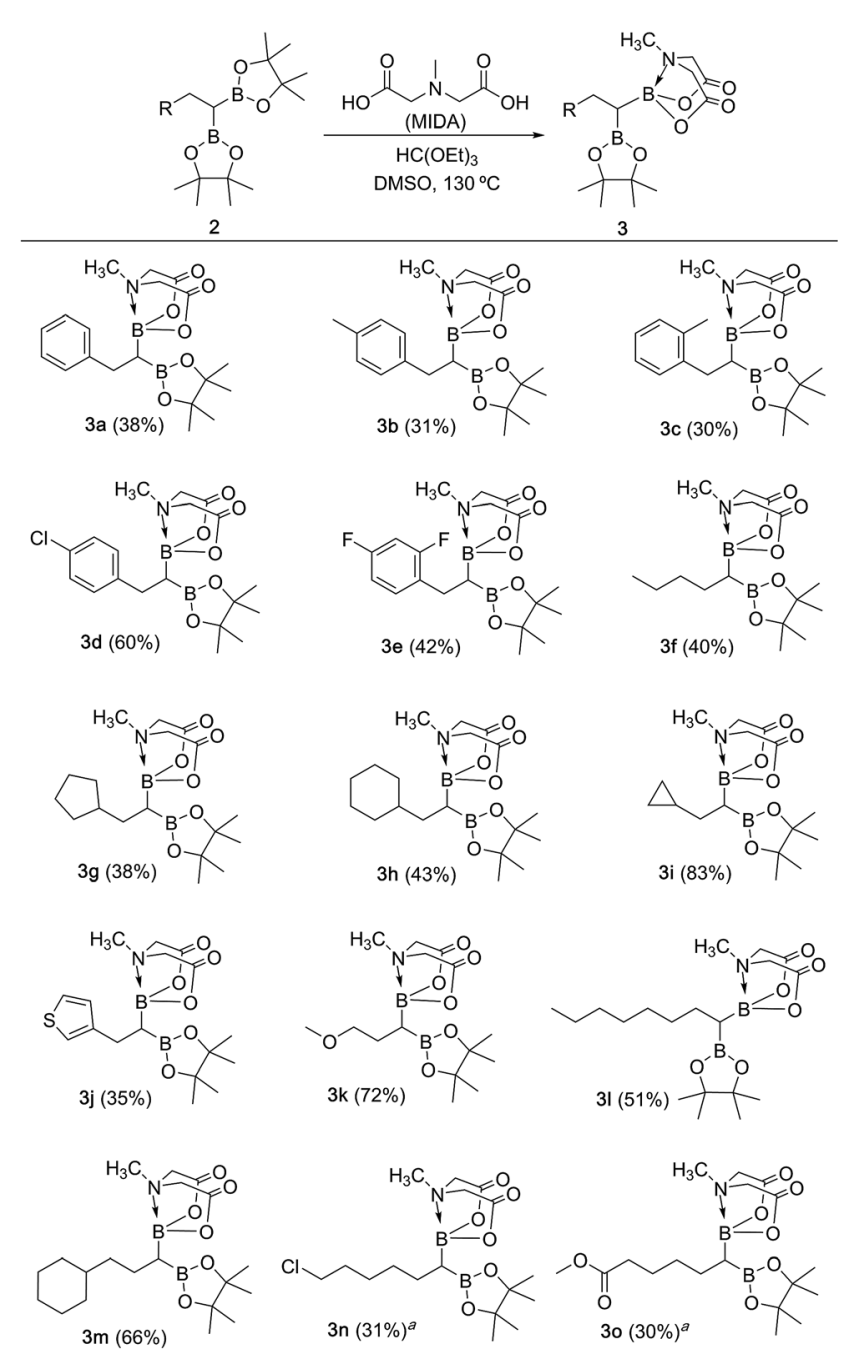

Scheme 4 Synthesis of unsymmetrical geminal diborylalkanes. Reaction conditions: 1,1-diboryl substrate 2 (1.3 mmol), N-methyliminodiacetic acid (6 equiv.), $\mathrm{HC}(\mathrm{OEt})_{3}$ (4 equiv.), DMSO, $130{ }^{\circ} \mathrm{C}, 15 \mathrm{~h}$. ${ }^{a}$ Reaction condition: (i) 1,1-diboryl substrate $(1.3 \mathrm{mmol}), \mathrm{NH}_{4} \mathrm{OAc}$ (3.1 equiv.), $\mathrm{NaIO}_{4}$ (3.1 equiv.), acetone : water $(2: 1), 80{ }^{\circ} \mathrm{C}, 2 \mathrm{~h}$; (ii) $\mathrm{N}$-methyliminodiacetic acid (6 equiv.), $\mathrm{HC}(\mathrm{OEt})_{3}$ (4 equiv.), DMSO, $115^{\circ} \mathrm{C}, 2 \mathrm{~h}$. 
Interestingly, our above method led to the conversion of only one of the $\mathrm{B}(\mathrm{Pin})$ groups of symmetrical geminal diborons into $\mathrm{B}$ (MIDA) group (3a-o, Scheme 4 ) as the di-B(MIDA) product was not detected. The unreacted symmetrical diboron substrates (2a-o) from above reaction were recovered and used again. To the best of our knowledge, this is the first example of unsymmetrical geminal diboryl compounds that possess $\mathrm{B}(\mathrm{Pin}) /$ B(MIDA) groups. ${ }^{11 a}$

With the unsymmetrical diboron compounds (3) in hand, we screened several conditions (see ESI, Table S2 $\dagger$ ) for chemoselective oxidation of 3 into $\alpha$-hydroxy MIDA boronate (4). These investigations revealed that use of sodium perborate ${ }^{16}(1.3$ equiv.) in a mixture of THF and buffer solution $\left(\mathrm{KH}_{2} \mathrm{PO}_{4} / \mathrm{NaOH}\right.$, $\mathrm{pH}=7$ ) afforded better conversion in comparison to Oxone. Importantly, MIDA boronate remained intact during this chemoselective oxidation (Scheme 5). Aqueous solutions of sodium perborate are basic and therefore the use of a buffer solution presumably prevented the deprotection of aq. base labile $\mathrm{B}$ (MIDA) group. This optimized protocol was also found to be

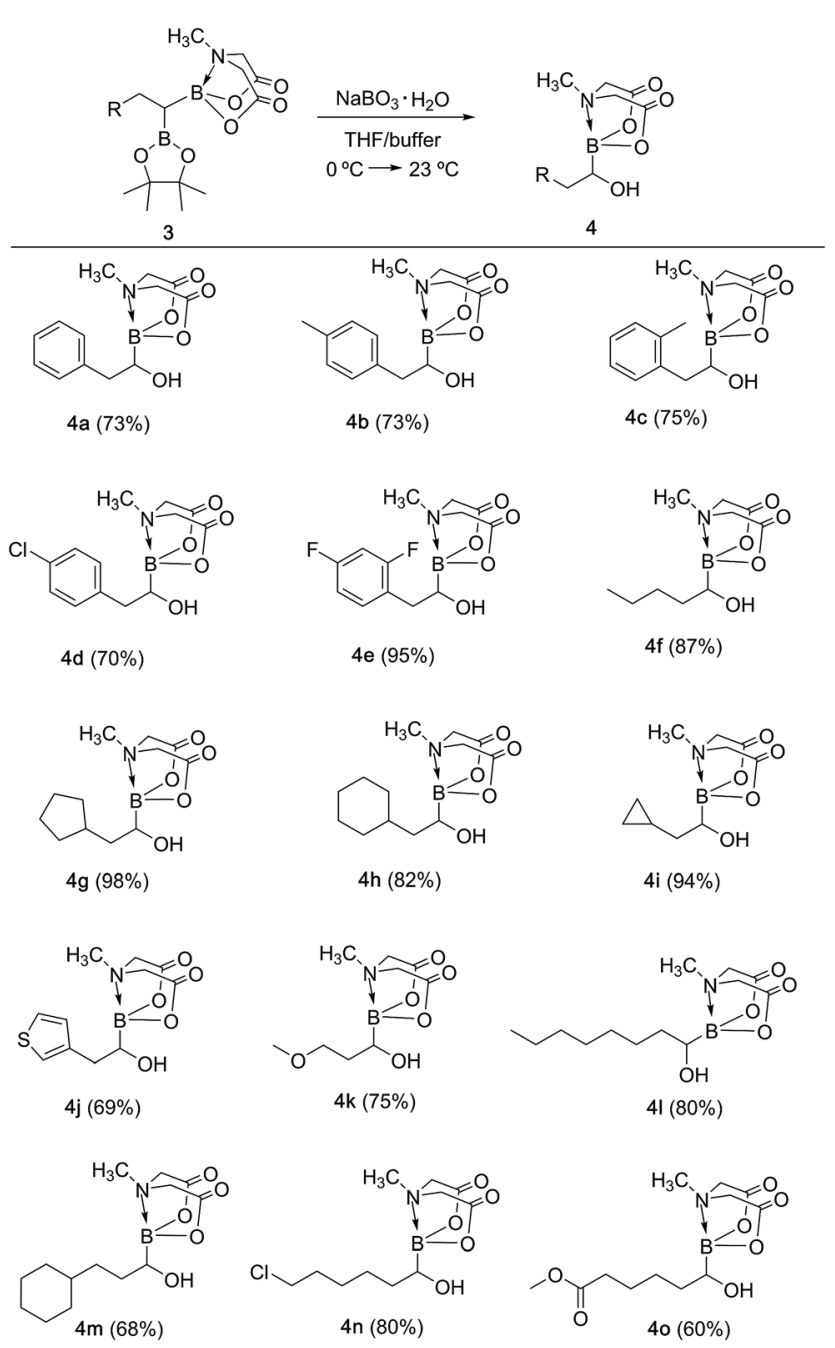

Scheme 5 Synthesis of $\alpha$-hydroxy MIDA boronates via chemoselective oxidation of unsymmetrical geminal diborylalkanes. Reaction conditions: 3 ( $0.6 \mathrm{mmol})$, sodium perborate monohydrate (1.3 equiv.), $\operatorname{THF}(2 \mathrm{ml})$, buffer $\left(\mathrm{KH}_{2} \mathrm{PO}_{4} / \mathrm{NaOH}, \mathrm{pH}=7\right), 23^{\circ} \mathrm{C}, 3 \mathrm{~h}$. compatible for mild and efficient oxidation of other diboron compounds (Scheme 5). In general, substrates possessing alkyl side chains provided higher yields than those with aromatic side chains. In particular, substrates possessing heteroaromatic scaffold (3j), alkyl halide (3n) and ester (3o) were also tolerated. Interestingly, a control reaction performed by treating the symmetrical diboron (2h) with $\mathrm{NaBO}_{3}$ (1.3 equiv.) in THF : buffer solution provided mainly the unreacted starting material (2h) after $4 \mathrm{~h}$. This result suggests that differential protection of geminal diborons with suitable boron ligands is critical to enable their chemoselective oxidation into stable $\alpha$ hydroxy boronates.

Having established a concise synthetic route to $\alpha$-hydroxy MIDA boronates, we next turned our attention to their oxidation

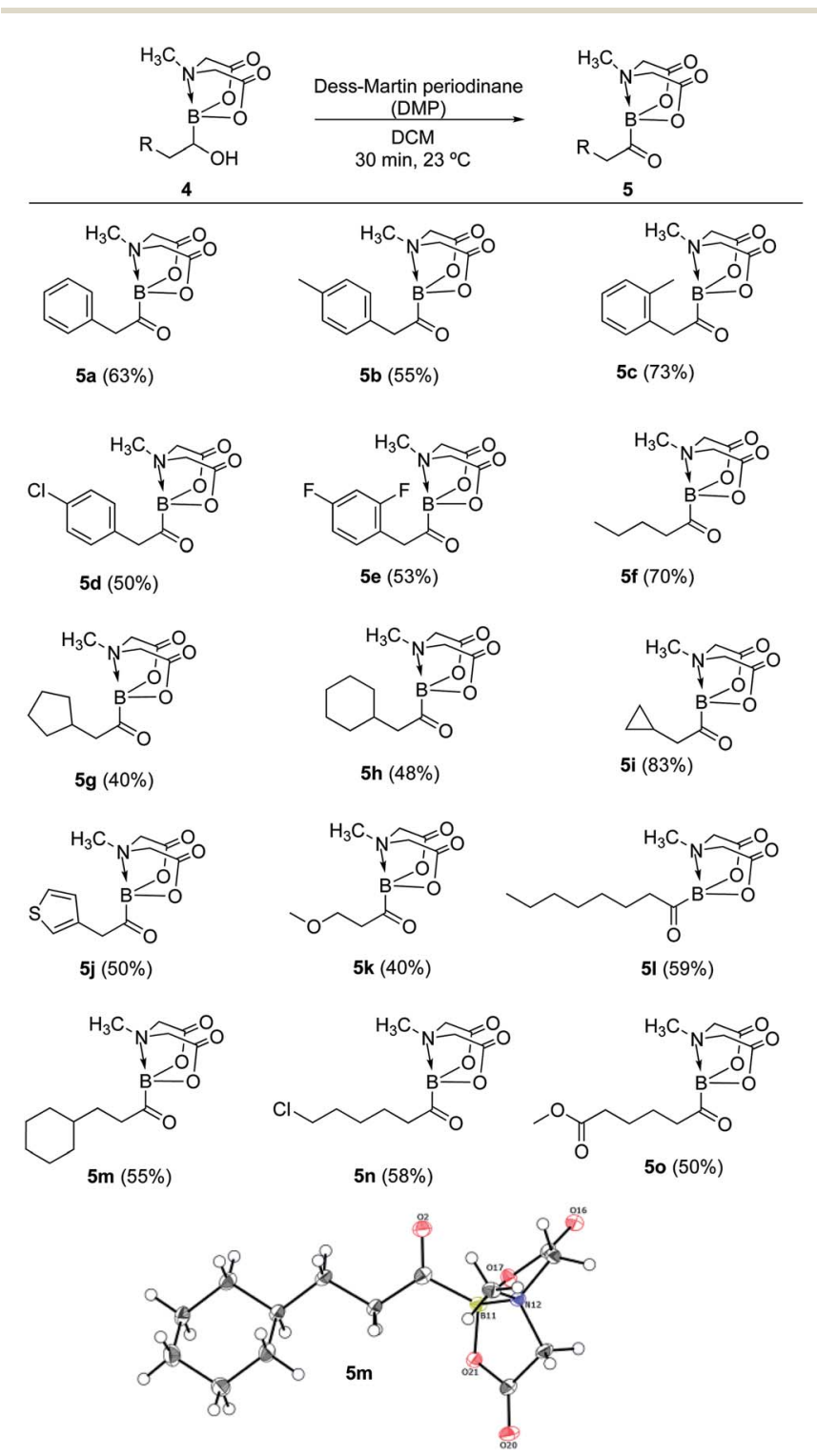

Scheme 6 Synthesis of MIDA acylboronates. Reaction conditions: 4 $(0.4 \mathrm{mmol}), \mathrm{DMP}\left(1.1\right.$ equiv.), DCM $(1.5 \mathrm{ml}), 23^{\circ} \mathrm{C}, 30 \mathrm{~min} . \mathrm{X}$-ray crystal structure of one of the novel acylboronates $(5 \mathrm{~m})$ is also shown. 
into acylboronates. All the above synthesized $\alpha$-hydroxy MIDA boronates were successfully oxidized into the corresponding MIDA acylboronates using 1.1 equiv. of $\mathrm{DMP}^{7 a}$ in DCM at $23{ }^{\circ} \mathrm{C}$ (Scheme 6). The structure of one of the novel acylboronates was confirmed by single crystal X-ray diffraction analysis (5m, Scheme 6). Significantly, this geminal borylation route also afforded a mild and direct access to acylboronate possessing a heteroaromatic scaffold (5j) from corresponding vinyl boronic ester $\left(\mathbf{1 j}^{\prime}\right)$. This route to heteroaromatic acylboronates is complimentary to previous approaches that involved the reaction of heteroaryl halides or acyl chlorides with organolithium ${ }^{6 b}$ or highly basic boron reagents. ${ }^{8 c}$

To further demonstrate the utility and unique versatility of diboryl alkane oxidation approach for modular synthesis of multifunctional acylboronates, we envisioned the use of commercially available bis[(pinacolato)boryl]methane (1" Scheme 7) as a key precursor for preparation of acylboronates that possess additional functional groups such as alkynes. $\mathbf{1}^{\prime \prime}$ can be easily prepared in the lab at $>1 \mathrm{~g}$ scale. ${ }^{11 b}$ Thus, deprotonation of $\mathbf{1}^{\prime \prime}$ with LDA followed by treatment with 6-iodo-1hexyne provided the geminal diboryl alkane (2p, Scheme 7) possessing a terminal alkyne group. Conversion of one of the $\mathrm{B}(\mathrm{Pin})$ groups of $2 \mathrm{p}$ into B(MIDA) followed by chemoselective oxidation of $\mathrm{B}(\mathrm{Pin})$ with sodium perborate furnished the corresponding $\alpha$-hydroxy MIDA boronate (4p). Oxidation of $4 p$ using DMP provided a straightforward access to the first MIDA acylboronate (5p, Scheme 7) possessing a terminal alkyne functional group. The presence of acylboron and alkyne functional groups in the same molecule allows some unique applications in chemical biology and organic synthesis because these compounds can participate in mutually orthogonal ${ }^{\mathbf{1 0}}$ bioorthogonal chemistry and cascade reactions. The only previous

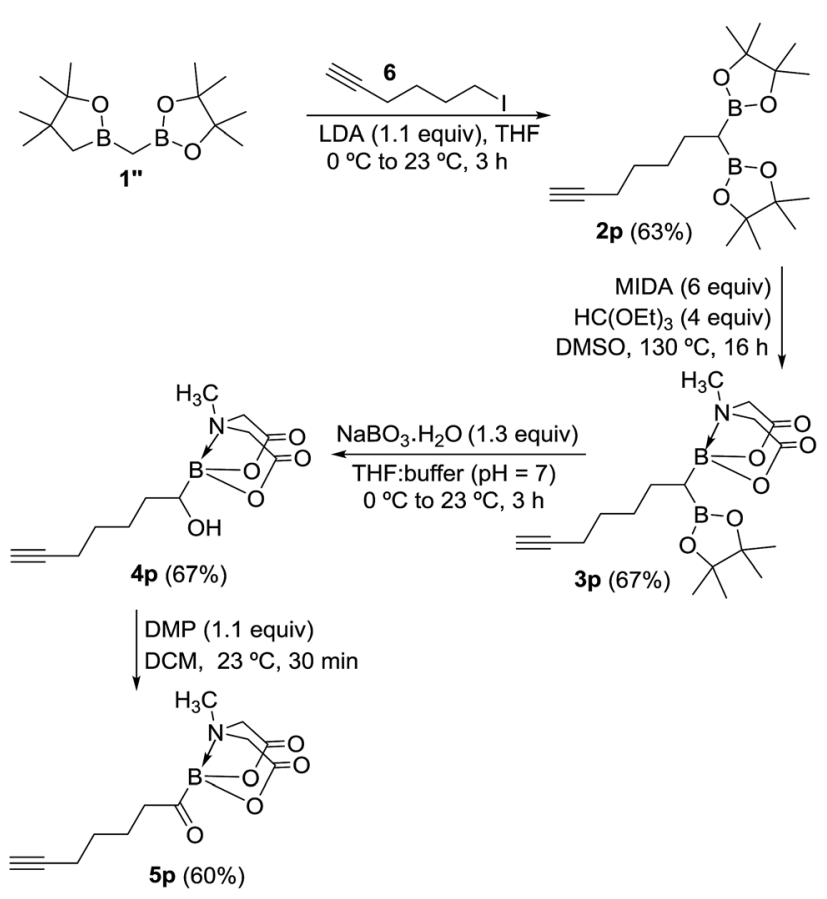

Scheme 7 Mild and concise route to alkynyl MIDA acylboronate. report for an alkynyl acylboron involved the use of BuLi and cryogenic temperature. ${ }^{\mathbf{1 0}}$

Inspired by the success of above approach, we hypothesized that chemoselective oxidation of $\mathrm{B}(\mathrm{Pin})$ in a differentially protected geminal diboron located at the allylic position of an alkene should provide access to a novel class of acylborons: $\alpha, \beta$ unsaturated MIDA acylboronates. Thus, allyl bromide (7) was converted into the homoallyl diboron compound (2q, Scheme 8) by treatment with deprotonated diborylmethane $\left(\mathbf{1}^{\prime \prime}\right) \cdot{ }^{16 a}$ Conversion of one of the $\mathrm{B}(\mathrm{Pin})$ groups of $\mathbf{2 q}$ into B(MIDA) provided the homoallylic unsymmetrical diboron (3q) which was isomerized to allylic diboron (3r) using a cationic $\mathrm{Ru}(\mathrm{II})$ complex. ${ }^{17}$ 3r was subjected to chemoselective oxidation protocol (Scheme 8) to provide the $\alpha$-hydroxy boronate (4q). Oxidation of this allylic alcohol using DMP afforded the targeted $\alpha, \beta$-unsaturated MIDA acylboronate (5q, Scheme 8 ) which was found to be stable to silica gel chromatography. To the best of our knowledge, this is the first report of an $\alpha, \beta$-unsaturated acylboron. This novel class of acylboronates would be difficult to synthesize using the conventional methods.

To gain deeper insights into the molecular structure of this novel $\alpha, \beta$-unsaturated acylboronate, single crystal X-ray diffraction analysis of $\mathbf{5 q}$ was conducted. ${ }^{\mathbf{1 8}}$ There were two molecules in the asymmetric unit. Interestingly, one of the independent molecules was exclusively s-trans (Fig. 1a) while
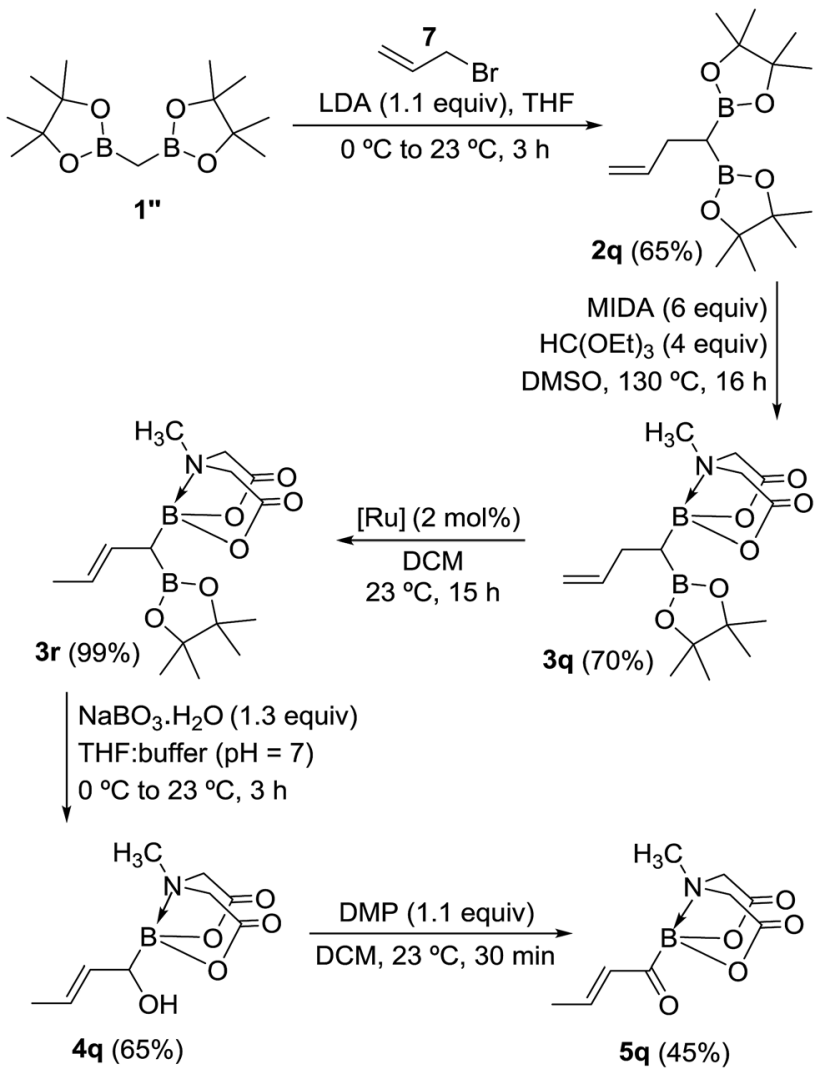

Scheme 8 Synthesis of a novel acylboron: $\alpha, \beta$-unsaturated acylboronate. $[\mathrm{Ru}]=[\mathrm{CpRu}(\mathrm{P}-\mathrm{N})(\mathrm{MeCN})] \mathrm{PF}_{6}\left(\mathrm{P}-\mathrm{N}=2-\mathrm{PiPr}_{2}-4-t \mathrm{Bu}-1-\mathrm{Me}-\right.$ imidazole). 


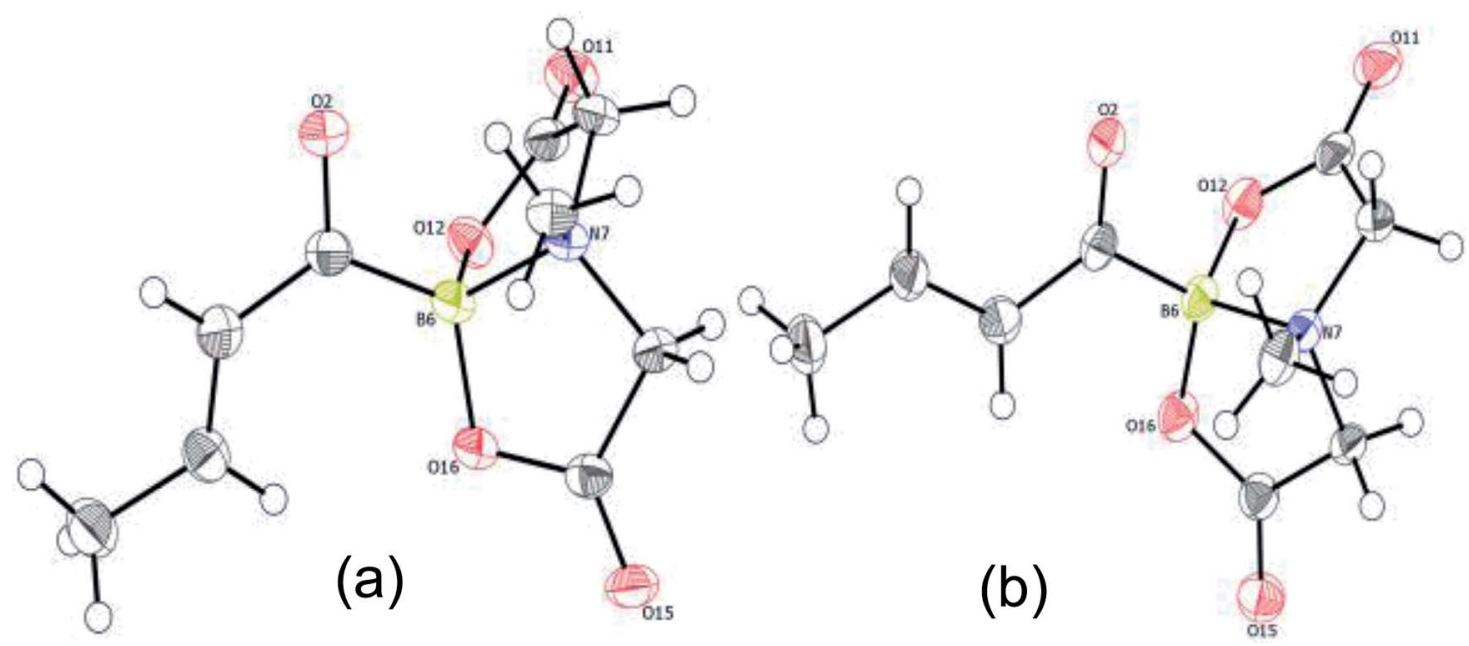

Fig. 1 X-ray crystal structure of $\alpha, \beta$-unsaturated acylboronate (5q). (a) s-trans isomer (b) $s$-cis isomer (the $10 \% \mathrm{~s}$-trans isomer has been omitted for better clarity).

the second molecule was predominantly s-cis (Fig. 1b). The $\mathrm{C}(\mathrm{O})$ $\mathrm{C}_{3} \mathrm{H}_{5}$ moiety in this second molecule (Fig. $1 \mathrm{~b}$ and ESI, Fig. S2 $\dagger$ ) was disordered in a 9:1 ratio by rotation around the $\mathrm{C}\left(\mathrm{sp}^{2}\right)$ $\mathrm{C}\left(\mathrm{sp}^{2}\right)$ bond, i.e. a $9: 1$ mixture of s-cis and s-trans isomers. The $\mathrm{C}=\mathrm{O}$ bond length in both of these isomers (1.234 and $1.237 \AA$ ) is similar to that of unconjugated acylborons $(1.234 \AA)^{6 e}$ but slightly longer than $\alpha, \beta$-unsaturated ketones/aldehydes $(1.222$ $\AA) .{ }^{19}$ The $\mathrm{C}=\mathrm{C}$ bond length $(1.317 \AA)$ of s-cis isomer is slightly shorter than that of s-trans isomer $(1.332 \AA)$ which is also shorter than $\alpha, \beta$-unsaturated ketones/aldehydes $(1.340 \AA) .{ }^{19}$ The $\mathrm{C}-(\mathrm{C}=\mathrm{O})-\mathrm{B}$ angle in case of s-trans $\left(125.95^{\circ}\right)$ isomer is larger than that found in typical trigonal planar systems $\left(120^{\circ}\right)$ as well as the s-cis isomer $\left(120.39^{\circ}\right.$, Fig. $\left.1 \mathrm{~b}\right)$. Presumably, this is due to increased repulsion between the olefin and boronate groups in case of s-trans isomer.

To further investigate the scope of our developed approach for synthesis of unsymmetrical geminal diborylalkanes (Scheme 4), two additional multiborylated substrates: diborylmethane $\left(\mathbf{1}^{\prime \prime}\right)$ and a 1,1,2-triB(Pin) compound (2t) were evaluated. Significantly, $\mathbf{1}^{\prime \prime}$ was also found to be compatible with the

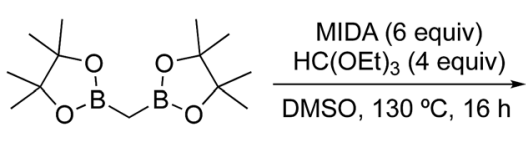

1"

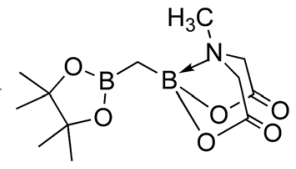

3s $(40 \%)$

$\mathrm{NaBO}_{3} \cdot \mathrm{H}_{2} \mathrm{O}$ (1.3 equiv) THF: buffer $(\mathrm{pH}=7)$ $0^{\circ} \mathrm{C}$ to $23^{\circ} \mathrm{C}, 3 \mathrm{~h}$<smiles>CC(=O)O[B-]12COC1N(C)C(=O)OC(=O)O2</smiles>
5s $(44 \%)$<smiles>CN1CC(=O)O[B-]2(CO)OC(=O)OC1O2</smiles>

$4 s(44 \%)$

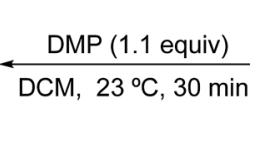

(
Scheme 9 Synthesis and oxidation of hydroxy methyl MIDA boronate. reaction conditions as the desired unsymmetrical diborylmethane (3s, Scheme 9) was obtained in $40 \%$ yield. $3 \mathrm{~s}$ was amenable to chemoselective oxidation to afford the hydroxy methyl MIDA boronate (4s). $4 \mathrm{~s}$ has been previously synthesized by Yudin and coworkers through an alternative approach and this compound is an important building block for construction of biologically important boron-containing heterocyclic compounds. ${ }^{20}$ Interestingly, oxidation of hydroxy methyl MIDA boronate (4s) using DMP provided the acetoxy MIDA boronate $(5 \mathbf{s})^{21}$ instead of the expected formyl boronate (Scheme 9). The structure of this acetoxy MIDA boronate was confirmed by X-ray diffraction (Fig. 2). Although the detailed mechanism for formation of $\mathbf{5 s}$ is not clear at this stage, this unexpected result could be due to the high reactivity/instability of formyl boronate and involvement of acetic acid byproduct generated during DMP mediated oxidation..$^{22}$

In contrast to the diborylmethane ( $\mathbf{1}^{\prime \prime}$, Scheme 9$)$ and several other geminal diborylalkanes (2a-o, Scheme 4) that underwent selective conversion into the unsymmetrical geminal diborons, a 1,1,2-triB(Pin) compound was not a suitable substrate. For instance, treatment of $2 \mathbf{t}$ (obtained via borylation of alkyne 8$)^{23}$ with MIDA (Scheme 10) provided a mixture (1:1 ratio, NMR) of the two mono-B(MIDA)-diB(Pin) compounds (3t and $3 \mathbf{t}^{\prime}$, Scheme 10) possessing $\mathrm{B}(\mathrm{MIDA})$ group vicinal to $\operatorname{diB}(\mathrm{Pin})$ or

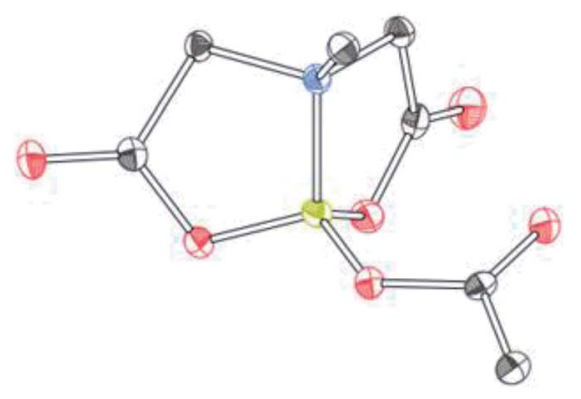

Fig. 2 X-ray crystal structure of acetoxy MIDA boronate (5s). 


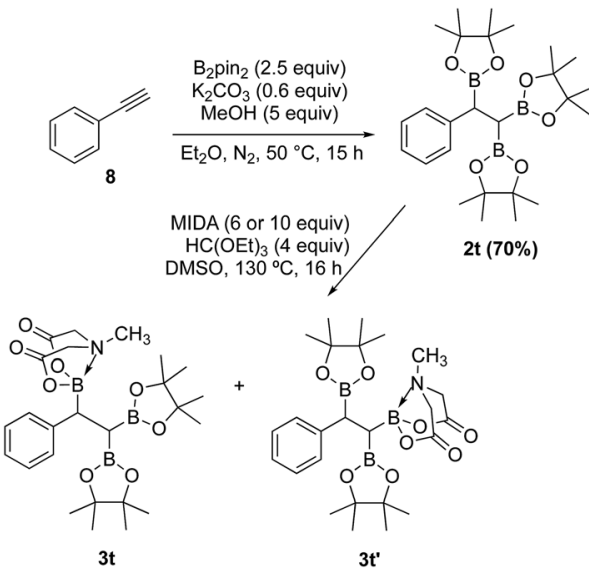

Scheme 10 Attempted synthesis of an unsymmetrical geminal diborylalkane from a 1,1,2-triB(Pin) compound (2t).

geminal to the $\mathrm{B}(\mathrm{Pin})$. This mixture was inseparable using silica gel chromatography due to very small $R_{\mathrm{f}}$ difference between the two compounds ( $\mathbf{3 t}$ and $\mathbf{3} \mathbf{t}^{\prime}$ ).

\section{Conclusions}

In summary, we have developed a novel and modular route to MIDA acylboronates from alkynes/alkenes or vinyl boronic esters. Our strategy involved synthesis of differentially protected geminal diboron compounds as key precursors that were amenable to chemoselective oxidation into MIDA acylboronates. Importantly, this new approach drastically reduces the number of steps required for synthesis of $\alpha$-hydroxy MIDA boronates and acyl boronates from readily available substrates such as terminal alkynes and vinyl boronic esters. To the best of our knowledge, this is the first report of chemoselective oxidation of geminal diborylalkanes. The methodology provided a concise and mild access to acylboronates possessing aliphatic, aromatic as well as the rarer heteroaromatic and alkynyl scaffolds which have applications in mutually orthogonal bioorthogonal chemistry. Significantly, the unique modularity of this methodology also opened up a facile access to a novel class of multifunctional acylborons: $\alpha, \beta$-unsaturated MIDA acylboronate. The availability of $\alpha, \beta$-unsaturated MIDA acylboronates is expected to open up exciting opportunities to design novel reactivity patterns and further expand the chemical space of acylborons and organoborons.

\section{Conflicts of interest}

There are no conflicts to declare.

\section{Acknowledgements}

We thank Dr Athula Attygalle and Zhaoyu Zheng for HRMS analysis. Financial support from Stevens Institute of Technology is gratefully acknowledged. Dr Daniel Paley performed single-crystal X-ray diffraction studies, prepared the thermal ellipsoid plots in Scheme 6, Fig. 1 and 2, and provided measurements/text concerning the X-ray analysis of compound 5q. Single-crystal diffraction was performed in the Shared Materials Characterization Laboratory at Columbia Nano Initiative (Columbia University).

\section{References}

1 (a) D. G. Hall, Boronic Acids, Wiley-VCH, Weinheim, 2006; (b) G. A. Molander, J. Org. Chem., 2015, 80, 7837.

2 (a) F. K. Scharnagl, S. K. Bose and T. B. Marder, Org. Biomol. Chem., 2017, 15, 1738; (b) J. D. St. Denis, Z. He and A. K. Yudin, ACS Catal., 2015, 5, 5373.

3 M. R. Ibrahim, M. Bühl, R. Knab and P. V. R. Schleyer, J. Comput. Chem., 1992, 13, 423.

4 M. Yamashita, Y. Suzuki, Y. Segawa and K. Nozaki, J. Am. Chem. Soc., 2007, 129, 9570.

5 G. A. Molander, J. Raushel and N. M. Ellis, J. Org. Chem., 2010, 75, 4304.

6 (a) A. M. Dumas and J. W. Bode, Org. Lett., 2012, 14, 2138; (b) G. Erős, Y. Kushida and J. W. Bode, Angew. Chem., Int. Ed., 2014, 53, 7604; (c) J. Taguchi, T. Ikeda, R. Takahashi, I. Sasaki, Y. Ogasawara, T. Dairi, N. Kato, Y. Yamamoto, J. W. Bode and H. Ito, Angew. Chem., Int. Ed., 2017, 56, 13847; (d) H. Noda and J. W. Bode, Chem. Sci., 2014, 5, 4328; (e) H. Noda and J. W. Bode, J. Am. Chem. Soc., 2015, 137, 3958; (f) S. M. Liu, D. Wu and J. W. Bode, Org. Lett., 2018, 20, 2378.

7 (a) Z. He, P. Trinchera, S. Adachi, J. D. St Denis and A. K. Yudin, Angew. Chem., Int. Ed., 2012, 51, 11092; (b) S. Adachi, S. K. Liew, C. F. Lee, A. Lough, Z. He, J. D. S. Denis, G. Poda and A. K. Yudin, Org. Lett., 2015, 17, 5594; (c) C. F. Lee, A. Holownia, J. M. Bennett, J. M. Elkins, J. D. St. Denis, S. Adachi and A. K. Yudin, Angew. Chem., Int. Ed., 2017, 56, 6264.

8 (a) M. L. Lepage, S. Lai, N. Peressin, R. Hadjerci, B. O. Patrick and D. M. Perrin, Angew. Chem., Int. Ed., 2017, 56, 15257; (b) M. Sajid, G. Kehr, C. G. Daniliuc and G. Erker, Angew. Chem., Int. Ed., 2014, 53, 1118; (c) J. Campos and S. Aldridge, Angew. Chem., Int. Ed., 2015, 54, 14159.

9 (a) A. M. Dumas, G. A. Molander and J. W. Bode, Angew. Chem., Int. Ed., 2012, 51, 5683; (b) C. J. White and J. W. Bode, ACS Cent. Sci., 2018, 4, 197; (c) H. Noda, G. Erös and J. W. Bode, J. Am. Chem. Soc., 2014, 136, 5611.

10 S. M. Liu, D. Mazunin, V. R. Pattabiraman and J. W. Bode, Org. Lett., 2016, 18, 5336.

11 (a) R. Nallagonda, K. Padala and A. Masarwa, Org. Biomol. Chem., 2018, 16, 1050; (b) K. Hong, X. Liu and J. P. Morken, J. Am. Chem. Soc., 2014, 136, 10581; (c) B. Potter, A. A. Szymaniak, E. K. Edelstein and J. P. Morken, J. Am. Chem. Soc., 2014, 136, 17918; (d) D. J. Blair, D. Tanini, J. M. Bateman, H. K. Scott, E. L. Myers and V. K. Aggarwal, Chem. Sci., 2017, 8, 2898; (e) S. A. Murray, J. C. Green, S. B. Tailor and S. J. Meek, Angew. Chem., Int. Ed., 2016, 55, 9065; (f) Y. Shi and A. H. Hoveyda, Angew. Chem., Int. Ed., 2016, 55, 3455; $(g)$ K. Endo, T. Ohkubo, M. Hirokami and T. Shibata, J. Am. 
Chem. Soc., 2010, 132, 11033; (h) Q. Huang and S. Z. Zard, Org. Lett., 2018, 20, 5304.

12 I. Marek and J.-F. Normant, Chem. Rev., 1996, 96, 3241.

13 (a) X. Li and D. G. Hall, Angew. Chem., Int. Ed., 2018, 57, 10304; (b) J. J. Molloy, T. A. Clohessy, C. Irving, N. A. Anderson, G. C. Lloyd-Jones and A. J. B. Watson, Chem. Sci., 2017, 8, 1551.

14 S. Lee, D. Li and J. Yun, Chem.-Asian J., 2014, 9, 2440.

15 E. P. Gillis and M. D. Burke, J. Am. Chem. Soc., 2007, 129, 6716.

16 (a) D. S. Matteson and R. J. Moody, Organometallics, 1982, 1, 20; (b) G. W. Kabalka, T. M. Shoup and N. M. Goudgaon, J. Org. Chem., 1989, 54, 5930.

17 T. Miura, J. Nakahashi, W. Zhou, Y. Shiratori, S. G. Stewart and M. Murakami, J. Am. Chem. Soc., 2017, 139, 10903.
18 CCDC 1880524 (5m), 1880525 (5q) and 1900591 (5s) contain the supplementary crystallographic data for this paper. $\dagger$

19 F. H. Allen, O. Kennard, D. G. Watson, L. Brammer, A. G. Orpen and R. Taylor, J. Chem. Soc., Perkin Trans. 2, 1987, 1, 1.

20 S. Adachi, A. B. Cognetta, M. J. Niphakis, Z. He, A. Zajdlik, J. D. St. Denis, C. C. G. Scully, B. F. Cravatt and A. K. Yudin, Chem. Commun., 2015, 51, 3608.

21 C. F. Lee, D. B. Diaz, A. Holownia, S. J. Kaldas, S. K. Liew, G. E. Garrett, T. Dudding and A. K. Yudin, Nat. Chem., 2018, 10, 1062.

22 D. B. Dess and J. C. Martin, J. Org. Chem., 1983, 48, 4155.

23 G. Gao, J. Yan, K. Yang, F. Chen and Q. Song, Green Chem., 2017, 19, 3997. 